DOI: 10.20472/IAC.2018.040.069

\author{
YU-LIN WANG \\ National Cheng Kung University, Taiwan
}

\title{
ENTREPRENEURIAL OPPORTUNITY RECOGNITION: A REVIEW OF LITERATURE
}

\begin{abstract}
:
Economic theory is the major theoretical perspective in entrepreneurship. Since entrepreneurial opportunity recognition is rooted in the entrepreneurship literature, it is necessary to understand the nature of entrepreneurial opportunity recognition from the economic theoretical perspective. Among the economic theory, entrepreneurship literature falls into two school of thoughts, neoclassical equilibrium theory and Austrian theory. The neoclassical equilibrium theory assumes that everyone can recognize all entrepreneurial opportunities, and it is individual's risk-propensity that determines who become the entrepreneurs (Khilstrom \& Laffont, 1979). However, the traditional neoclassical equilibrium theory fails to explain the framework of entrepreneurship and the existence of entrepreneurial opportunities (Eckhardt \& Shane, 2003).

Austrian theory assumes that people cannot recognize all opportunities. Austrian theory emphasizes that it is the imperfect market with information asymmetry that generates the information gap. In other words, opportunities do not appear in a well-packaged informational form (Venkataraman, 1997). Kirzner (1997) has indicated that the distribution of information in society influences the discovery of entrepreneurial opportunities, and only a small subset of individuals are able to identify and recognize particular opportunity in the market. In addition, the process of discovering opportunities depends on people's ability and willingness to discover them. For example, people might not be able or may be unwilling to pay attention to external environment changes, which may lead to loss of the opportunity (Stevenson \& Gumpert, 1985). Only those who recognize the existence of opportunities and value them can then earn profits from these new opportunities (Ardichvili, Cardozo, \& Ray, 2003; Shane, 2000; Shane \& Venkataraman, 2000). That is, under the asymmetry of information circumstances, individuals with special insights and knowledge to discover and recognize entrepreneurial opportunities tend to be successful while others not able to recognize the opportunities or only see the risk for failure (Ulhøi, 2005). Since economic theory cannot fully explain the entrepreneurial opportunity recognition, scholars have shifted the focus to two different social science disciplines, psychology and sociology, to create theoretical frameworks to explain the process of opportunity recognition. In other words, the entrepreneurial opportunity recognition process can be investigated from personal cognitive framework and social context. Therefore, the purpose of this study is to review the literature and investigate the antecedents of entrepreneurial opportunity recognition.
\end{abstract}

\section{Keywords:}

Entrepreneurial Opportunity Recognition; Economic Theory, Psychology Theory

JEL Classification: M10, M19, M00 